International Journal of Business Management and Economic Review

Vol. 4, No. 05; 2021

ISSN: 2581-4664

\title{
SUSTAINABILITY THOUGHTS 151: AN OVERVIEW OF MARKET VARIABILITY BASED ON DOMINANT COMPONENT EQUALITY AND FREEDOM: WHAT IS THE STRUCTURE OF A TRUE PERFECT MARKET?
}

\author{
Lucio Muñoz* \\ *Independent Qualitative Comparative Researcher / Consultant, Vancouver, BC, Canada
}

\begin{abstract}
Markets are related to concepts like equality and freedom. Markets based on dominant component freedom are said to be perfect markets and markets based on dominant component equality are said to be imperfect markets. Perfect markets here assume dominant component equality neutrality; and imperfect markets in this context assume dominant component freedom neutrality. However, true perfect markets are associated with dominant component freedom and dominant component equality at the same time; and if one component is absent or assumed away or assumed irrelevant, then we have a true imperfect market. This means that true perfect and true imperfect market thinking is not the same as traditional perfect and imperfect market thinking as we know it as then a known perfect market may not be a true perfect market; and a true imperfect market can be even a perfect market if neutrality assumptions are at play. Hence there is need to state and generalize the meaning of true perfect markets to understand the nature of related imperfect markets and to make sense as to whether or not well-known perfect markets and imperfect markets are consistent with what is a true perfect market. And this raises the question how a market variability model based on dominant component equality and freedom looks like? What is the structure of a true perfect market? What is the structure of true imperfect markets? How can true market thinking be linked to the structure of two well-known markets, the Adam Smith's traditional perfect market; and the Karl Marx's red socialism market? The focus of this paper is to provide an overview of market variability based on dominant component equality and freedom to state the specific and the general structure of a true perfect market and of true imperfect markets; and linked this knowledge to the necessary and sufficient conditions for the existence of two well-known markets, the traditional perfect market and the red socialism market.
\end{abstract}

Key Words: True perfect market, true imperfect market, the traditional perfect market a la Adam Smith, the red socialism market a la Karl Marx, the liberal market, the authoritarian market, market variability, equality, freedom, market structure.

\section{INTRODUCTION}

\section{a) Markets and equality and freedom}

Markets are related to concepts like equality and freedom. For example, the traditional perfect market of Adam Smith is a freedom based perfect market, a market where dominant component freedom, economic freedom, rules regardless of equality. Equality is an exogenous factor in the 
perfect traditional market as this perfect market has an implicit economic equality neutrality assumption. It is known that the world of Adam Smith is based on economic freedom only(Smith 1776). Authoritarian based markets on the other hand, like economic authoritarianism are imperfect markets based on dominant component equality, but no freedom. Freedom here is an exogenous issue as these imperfect markets have an implicit economic freedom neutrality assumption. The same holds true for social authoritarianism based markets like the red socialism market of Karl Marx(Marx and Engels 1848) as here there is social equality, but no freedom. Notice that there are other perfect markets possible other than the traditional market like the perfect social market and the perfect red market; and that they have also related authoritarianism based markets like social authoritarianism(the red socialism market) and authoritarianism based red markets. In other words, markets, perfect or imperfect markets, can be dominant component freedom based or dominant component equality based if we assumed dominant component equality neutrality or dominant component freedom neutrality respectively.

\section{b) The nature of true perfect markets and true imperfect markets}

However, true perfect markets are linked to both dominant component equality and to dominant component freedom at the same time while true imperfect markets are linked to either dominant component freedom or to dominant component equality only. This means that true perfect markets may be inconsistent with known perfect market structures and that true imperfect markets may be consistent with known perfect and imperfect market structures. Moreover, from the true perfect market angle it is possible to see how imperfect markets can become perfect markets if we assume away either equality or freedom or if we declare any of them irrelevant. Ideas on how perfect market variability based on component dominance can be framed have recently been shared(Muñoz 2021) as well as ideas related to linking perfect market thinking to inclusion so as the need for full socio-economic inclusion when in the world of perfect red markets(Muñoz 2016a), the need for full socio-environmental-economic inclusion when in the world of perfect sustainability markets(Muñoz 2016b), and the need for full eco-economic inclusion when in the world of perfect green markets(Muñoz 2016c).

c) The need to understand the link between true perfect and true imperfect markets and all possible markets in terms of equality and freedom.

Hence based on the discussion above there is need to state and generalize the meaning of true perfect markets to understand the nature of related imperfect markets and to make sense as to whether or not known perfect markets and imperfect markets are consistent with what is a true perfect market. And this raises the question how a market variability model based on dominant component equality and freedom looks like? What is the structure of a true perfect market? What is the structure of true imperfect markets? How can this be linked to the structure of two wellknown markets, one perfect market known as Adam Smith's traditional perfect market; and one imperfect market known as Karl Marx's red socialism market? The focus of this paper is to provide an overview of market variability based on dominant component equality and freedom to state the general structure of a true perfect market and of true imperfect markets; and linked this knowledge to the necessary and sufficient conditions for the existence of two well-known markets, the traditional perfect market and the red socialism market. 
International Journal of Business Management and Economic Review

Vol. 4, No. 05; 2021

ISSN: 2581-4664

\section{OBJECTIVES}

This paper has the following goals: 1) to state the market variability model in terms of dominant component equality and freedom as well as to highlight the characteristics of the four specific type of markets possible; b) to use this framework to point out the structure of fully unsustainable markets, the structure of true imperfect markets, and the structure of a true perfect market; and c) to generalize this framework and then link the resulting true perfect and imperfect market thinking to known perfect market thinking such as the Adam Smith's perfect traditional market; and to known imperfect market thinking such as the Karl Marx's red socialism market.

\section{METHODOLOGY}

1) The terminology used in this paper is introduced;2) Some operational concepts are given; 3) The dominant component market variability model based on equality(E) and freedom(F) under externality neutrality assumptions is stated; 4) The 4 specific cases of model $\mathrm{Mj}$ possible are covered in detail and the implications in terms of true perfect market and true imperfect market thinking are highlighted; 5) The specific dominant component market $\mathrm{M}=\mathrm{X}$ is linked with its variability in terms of equality and freedom as given by specific variability model $M_{j}$; 6) The general dominant component market $M_{i}=X_{i}$ is linked with its variability in terms of equality and freedom as given by general variability model $\mathrm{M}_{\mathrm{ij}}$; 7) The case of the perfect economy market is described by making $\mathrm{M}_{\mathrm{i}}=\mathrm{X}_{\mathrm{i}}=\mathrm{B}$, where $\mathrm{B}=$ Economy, to make it possible to link true perfect economy thinking to perfect economy market thinking a la Adam Smith; 8) The case of the perfect social market is discussed by making $M_{i}=X_{i}=A_{i}$, where $A=$ Society, to make it possible to link true perfect social market thinking to imperfect social market thinking a la Karl Marx; And 9) Some food for thoughts and relevant conclusions are shared.

\section{Terminology}

$\mathrm{X}=$ Dominant component $\mathrm{X}$

$\mathrm{B}=$ Dominant economy

A $=$ Dominant society

$\mathrm{C}=$ Dominant environment

$\mathrm{M}=$ Perfect market $\mathrm{M}$

$\mathrm{Mi}=$ Perfect market $\mathrm{Mi}$

$[\mathrm{N}]=$ Market $\mathrm{N}$ under authoritarianism

$\mathrm{TM}=$ The perfect traditional market

$\mathrm{ENM}=$ The perfect environmental market

$\mathrm{RM}=$ The perfect red market

$\mathrm{S}=$ The perfect sustainability market

$\{\mathrm{M}\}=$ Market $\mathrm{N}$ under freedom, but not equality $\mathrm{M}=$ Market under equality and freedom

$\mathrm{FUM}=\mathrm{abc}=$ Full unsustainability market

TPM $=$ The true perfect market

TIM1 $=$ The true imperfect market type 1

$\mathrm{x}=$ Passive component $\mathrm{X}$

$\mathrm{b}=$ Passive economy

$\mathrm{a}=$ Passive society

$\mathrm{c}=$ Passive environment

$[\mathrm{M}]=$ Imperfect market $\mathrm{M}$

[Mi] = Imperfect market Mi

$\{\mathrm{N}\}=$ Market $\mathrm{N}$ under liberalism

$\mathrm{DS}=$ The perfect social market

$\mathrm{GM}=$ The perfect green market

TPEM $=$ The true perfect economy market

TPSM $=$ The true perfect social market

TISM $=$ The true imperfect social market

$\mathrm{SGi}=$ Sustainability gap " $\mathrm{i}$ "

TIM $=$ The true imperfect market

TIM2 $=$ The true imperfect market type 2

TIEM $=$ The true imperfect economy market

TIEM1 $=$ True imperfect economy market type 1

TIEM 2 = True imperfect economy market type 2 
International Journal of Business Management and Economic Review

Vol. 4, No. 05; 2021

ISSN: 2581-4664

TISM1 = True imperfect social market type $1 \quad$ TISM2 = True imperfect social market type 1

Operational concepts and types of perfect market structures

a) Operational concepts

1) Perfect market, a market where there is dominant component equality and freedom

2) Imperfect market, a market where there is component equality, but not freedom

3) Perfect paradigm shift, a shift from a perfect market to a higher level perfect market

4) Paradigm management, the handling of cost externalization through externality management

5) Paradigm flip, a flip to the inverse opposite paradigm

6) Perfect paradigm flip, a flip to the perfect inverse opposite paradigm

7) Imperfect paradigm flip, a flip to the imperfect inverse opposite paradigm

8) Authoritarian market, an imperfect market

9) Sustainability market, the perfect market where there is full co-component equality and freedom

10) Externality management market, the market where there is partial co-component equality, but no freedom.

11) Imperfect paradigm shift, a shift from a perfect market to a higher level imperfect market

b) Type of perfect market structures

Given the dummy market models with two components $M_{1}=X y$ and $M_{2}=x Y$, the following can be said about different market structures:

1) Perfect markets

There is dominant component equality and freedom

$\mathbf{M}_{1}=\mathbf{X y}=\mathbf{A}$ dominant component $\mathrm{X}$ perfect market

$M_{2}=x Y=A$ dominant component $Y$ perfect market

M3 $=$ XY = A co-dominant component $X Y$ perfect market

You can appreciate that when there is both component equality and freedom at the same time you have a true perfect market.

2) Imperfect markets type 1

There is dominant component equality, but no freedom, they are dictatorship based markets

$\left[M_{1}\right]=[X] y=A$ dominant component $X$ imperfect market type 1

$\left[\mathrm{M}_{2}\right]=\mathrm{x}[\mathrm{Y}]=\mathrm{A}$ dominant component $\mathrm{Y}$ imperfect market type 1

$[\mathrm{M} 3]=[\mathrm{XY}]=\mathrm{A}$ co-dominant component $\mathrm{XY}$ imperfect market type 1

You can see that when there is only component equality you have an imperfect market type 1.

3) Imperfect markets type 2

There is dominant component freedom, but no equality, they are liberalism based markets

$\left\{M_{1}\right\}=\{X\} \mathbf{y}=$ A dominant component $X$ imperfect market type 2

$\left\{M_{2}\right\}=x\{Y\}=A$ dominant component $Y$ imperfect market type 2

$\{\mathrm{M} 3\}=\{\mathrm{XY}\}=\mathrm{A}$ co-dominant component $\mathrm{XY}$ imperfect market type 2

Notice that when there is only component freedom again you have an imperfect market type 2 . 
International Journal of Business Management and Economic Review

Vol. 4, No. 05; 2021

ISSN: 2581-4664

c) Perfect markets and imperfect markets under sustainability gap pressures

Notice that if we make the passive component " $y$ " and passive component " $x$ " the sustainability gap pressures(SG) affecting all those perfect and imperfect market structures described above so that $\mathrm{SG}_{\mathrm{Y}}=\mathrm{y}$ and $\mathrm{SG}_{\mathrm{X}}=\mathrm{x}$, we can rewrite all those market structures above as when under binding sustainability gap pressures $\mathrm{SG}_{\mathrm{Y}}$ and $\mathrm{SG}_{\mathrm{X}}$. For example, rewriting all market structures of Market $M_{1}$ in terms of binding sustainability gaps we get the following structures:

i) The perfect market M1 under binding sustainability gap pressures $\mathbf{M}_{1}=\mathrm{Xy}=\mathrm{X} . \mathrm{SG}$ since $\mathrm{SG}_{\mathrm{Y}}=\mathbf{y}$

A dominant component $\mathrm{X}$ perfect market M1 under binding sustainability gap pressures SGy.

ii) The imperfect market $\mathrm{M} 1$ type 1 under binding sustainability gap pressures $\left[\mathbf{M}_{1}\right]=[\mathbf{X}] \mathbf{y}=[\mathbf{X}] . \mathbf{S G}_{\mathbf{Y}}$ since $\mathbf{S G}_{\mathbf{Y}}=\mathbf{y}$

A dominant component $\mathrm{X}$ imperfect market $\mathrm{M} 1$ type 1 under binding sustainability gap pressures $\mathrm{SG}_{\text {. }}$.

ii) The imperfect market $M 1$ type 2 under binding sustainability gap pressures $\left\{\mathbf{M}_{1}\right\}=\{\mathbf{X}\} \mathbf{y}=\{\mathbf{X}\} . \mathbf{S G}_{\mathbf{Y}}$ since $\mathbf{S G}_{\mathbf{Y}}=\mathbf{y}$

A dominant component $\mathrm{X}$ imperfect market $\mathrm{M} 1$ type 2 under binding sustainability gap pressures $\mathrm{SG}_{\mathrm{Y}}$.

The dominant component market variability model based on equality $(E)$ and freedom(F) under externality neutrality assumptions

If we assume there is dominant component market world $(\mathrm{M}=\mathrm{X})$, then its variability in terms of component equality(E) and component freedom(F) can be stated as follows:

1) $M_{j}=X_{E}+X_{F}$

The expression 1) above simply says that there can be " $\mathrm{j}$ " types of model $\mathrm{M}$ depending on whether there is only dominant component equality present $\left(\mathrm{X}_{\mathrm{E}}\right)$ or only dominant component freedom present $\left(\mathrm{X}_{\mathrm{F}}\right)$ is present or both dominant component equality and freedom are present $\left(\mathrm{X}_{\mathrm{EF}}\right)$ at the same time or both dominant component equality and freedom are absent $\left(\mathrm{X}_{\mathrm{ef}}\right)$ at the same time

Based on presence-absent thinking, the number of models that can be derived from model $\mathrm{Mj}$ is given by the formula $(\mathrm{a})^{\mathrm{n}}=(2)^{\mathrm{n}}=(2)^{2}=4$ models since $\mathrm{a}=$ dichotomy option presentabsent per variable $=2$; and $\mathrm{n}=$ number variables $=2$, and these models are described below:

Overview of the 4 cases of model Mj possible

i) The case of no dominant component equality $(e)$ and no freedom( $f$ ) so that $j=0$

This is the case of the fully imperfect market as there is no dominant component equality and freedom at the same time as indicated below:

2) $\mathbf{M}_{\mathbf{0}}=\left(\mathbf{X}_{\mathrm{e}} \cdot \mathbf{X}_{\mathrm{f}}\right)=\mathbf{X}_{\mathrm{ef}}=\mathbf{x}$

The expression 2) above is the expression of a fully unsustainable market as both dominant component equality and freedom $X_{\text {ef }}$ are missing at the same time, so then

3) $\mathbf{M}_{\mathbf{0}}=\mathbf{X}_{\text {ef }}=\mathbf{x}=\mathbf{a}$ fully unsustainable market(FUM)

Hence $\mathrm{M}_{0}$ is a fully unsustainable market(FUM) where there is neither dominant component equality nor freedom $\left(\mathrm{X}_{\mathrm{ef}}\right)$ at the same time so $\mathrm{M}_{0}=\mathrm{x}$. Hence, a lower case " $\mathrm{x}$ " means a fully unsustainable market $\mathrm{M}$. 
International Journal of Business Management and Economic Review

Vol. 4, No. 05; 2021

ISSN: 2581-4664

ii) The case of dominant component equality $(E)$, but no freedom( $f$ ) so that $j=1$

This is the case of the partially perfect market type 1 where there is only dominant component equality $\left(\mathrm{X}_{\mathrm{E}}\right)$ present as indicated below:

4) $\mathbf{M}_{1}=\left(\mathbf{X}_{\mathrm{E}}\right) \cdot \mathbf{X}_{\mathrm{f}}=\mathbf{X}_{\mathrm{Ef}}$

As there is no dominant component freedom( $\mathrm{Xf})$, this is a dictatorship based market so that:

5) $M_{1}=X_{E f}=[X]=$ dictatorship based market

This is a dominant component $\mathrm{X}$ dictatorship based market as there is dominant component equality without freedom $\mathrm{X}_{\mathrm{Ef}}$; and therefore $\mathrm{M}_{1}=[\mathrm{X}]$. Here it is assumed that freedom(f) does not matter, only dominant component equality $\mathrm{X}_{\mathrm{E}}$ matters, and this assumption makes it a true imperfect market type $1\left(\mathrm{TIM}_{1}\right)$. The sign [ ] means equal but not free market $\mathrm{M}$.

iii) The case of dominant component freedom $(F)$, but no equality(e) so that $j=2$

This is the case of the partially perfect market type 2 where there is only dominant component freedom $X_{\mathrm{F}}$ at work as shown below:

6) $\mathbf{M}_{2}=\left(\mathbf{X}_{\mathrm{e}}\right) \cdot \mathbf{X}_{\mathbf{F}}=\mathbf{X}_{\mathrm{eF}}$

Expression 6) tells us that $\mathrm{M}_{2}$ is a freedom based liberal market as there is dominant component freedom without equality $\mathrm{X}_{\mathrm{eF}}$ present.

As there is no dominant component equality $\mathrm{X}_{\mathrm{e}}$ this is a pure freedom based liberal market in $\mathrm{M}_{2}$, which means the following:

7) $M_{2}=X_{e F}=\{X\}=$ freedom based liberal market

Expression 7) indicates that market $\mathrm{M}_{2}$ assumes that equality(e) does not matter only dominant component freedom $\mathrm{X}_{\mathrm{F}}$ matters; and this assumption makes it a true imperfect market type 2(TIM 2$)$. The sign \{ \} means free but not equal market $\mathrm{M}$.

iv) The case of both dominant component equality $(E)$ and freedom $(F)$ so that $j=3$

This is the case of the fully perfect market where there is dominant component equality and freedom at the same time $\mathrm{X}_{\mathrm{EF}}$ at work as described below:

8) $\mathbf{M}_{3}=\left(\mathbf{X}_{\mathbf{E}}\right)\left(\mathbf{X}_{\mathbf{F}}\right)=\mathbf{X}_{\mathbf{E F}}$

As model $\mathrm{M}_{3}$ above is the true perfect market $\mathrm{X}$ as there is dominant component equality $\mathrm{X}_{\mathrm{E}}$ and dominant component freedom $\left(\mathrm{X}_{\mathrm{F}}\right)$ at that same time, which leads to:

9) $M_{3}=X_{E F}=X=T P M_{X}=$ the true perfect market $X$

The true perfect market X(TPMx) reflects equality and freedom at the same time so that $\mathrm{M}_{3}=\mathrm{X}$. Hence, a capital $\mathrm{X}$ means an equal and free market $\mathrm{M}$.

\section{Implications:}

1- The necessary and sufficient conditions for a true perfect market(TPM) to exist in a system based on component dominance such as $\mathrm{M}=\mathrm{X}$ is the existence of both dominant component equality and dominant component freedom at the same time such as in the case of $\mathrm{M}_{3}$ $\mathrm{X}_{\mathrm{EF}}=\mathrm{X}=\mathrm{TPM}_{\mathrm{X}}$; and

2- When there is only dominant component equality $X_{\mathrm{E}}$ or there is only dominant component freedom $\mathrm{X}_{\mathrm{F}}$ we do not have a true perfect market, but a true imperfect market(TIM). In the case of only dominant component equality we have a true imperfect markets type 1 like $\mathrm{M}_{1}=[\mathrm{X}]=\mathrm{TIM}_{1}$; and in the case of only dominant component freedom we have a true imperfect market type 2 like $\mathrm{M}_{2}=\{\mathrm{X}\}=\mathrm{TIM}_{2}$. 
International Journal of Business Management and Economic Review

Vol. 4, No. 05; 2021

ISSN: 2581-4664

\section{Linking market $\mathrm{M}=\mathrm{X}$ with its variability in terms of equality and freedom}

As it can be seen in Table 1 below, Model $\mathrm{M}=\mathrm{X}$ can take different forms, it can be fully unsustainable with the structure in column $\mathrm{M}_{0}$, it can be a dictatorship is in column $\mathrm{M} 1$, it can be a liberal market as in column $\mathrm{M}_{2}$ or it can be a true perfect market as in column $\mathrm{M}_{3}$.

Table 1

Summarizing the variability of model $\mathrm{M}=\mathrm{X}$ in terms of equality and freedom

\begin{tabular}{|c|c|c|c|c|}
\hline & $\mathrm{M}_{0}$ & $\mathrm{M}_{1}$ & $\mathrm{M}_{2}$ & $\mathrm{M}_{3}$ \\
\hline \multirow[t]{4}{*}{$\mathrm{M}=\mathrm{X}$} & $\mathrm{x}$ & {$[\mathrm{X}]$} & $\{X\}$ & $\mathrm{X}$ \\
\hline & Unsustainable & Dictatorship & Liberal & Equal and Free \\
\hline & Market & Market & Market & Market \\
\hline & $\begin{array}{l}\text { Fully imperfect } \\
\text { Market }\end{array}$ & $\begin{array}{l}\text { True imperfect } \\
\text { Market type } 1\end{array}$ & $\begin{array}{l}\text { True imperfect } \\
\text { Market type } 2\end{array}$ & $\begin{array}{l}\text { True perfect } \\
\text { Market }\end{array}$ \\
\hline
\end{tabular}

Implications from Table 1 with respect to model $M=X$

a) We can see in column $M_{0}$ that when model $M$ takes a fully imperfect market form where there is no dominant component equality and freedom at the same time $\left(\mathrm{X}_{\mathrm{ef}}\right)$ it is a fully unsustainable market " $\mathrm{x}$ "; $b$ ) We can appreciate in column $M_{1}$ that when model $M$ takes the form of a true imperfect market type 1 it is a dictatorship based market $\left(\mathrm{X}_{\mathrm{Ef}}=[\mathrm{X}]\right)$ as there is no dominant component freedom; c) we can read in column $\mathrm{M}_{2}$ that model $\mathrm{M}$ takes the form of a true imperfect market type 2 it is a freedom based liberal market $(\mathrm{XeF}=\{\mathrm{X}\})$ as equality does not matter; and d) we can see in column $\mathrm{M}_{3}$ that when model $\mathrm{M}$ takes a true perfect market form as there is both dominant component equality and freedom $\left(\mathrm{X}_{\mathrm{EF}}=\mathrm{X}\right)$ at the same time then it is an equal and free market as then full inclusion matters.

Generalizing the dominant component perfect market variability model based on equality and freedom under externality neutrality assumptions

We can generalize the information in Table 1 above if make $M=M i$ and $X=X i$ to reflect all possible dominant component market so that model $\mathrm{Mi}=\mathrm{Xi}$ can take different forms as indicated in Table 2 below:

Table 2

Generalizing the variability of model $\mathrm{M}=\mathrm{X}$ in terms of equality and freedom by making $\mathrm{M}=\mathrm{M}_{\mathrm{i}}$ and $\mathrm{X}=\mathrm{X}_{\mathrm{i}}$

\begin{tabular}{|c|c|c|c|c|}
\hline & $\mathrm{M}_{0}$ & $\mathrm{M}_{1}$ & $\mathrm{M}_{2}$ & $\mathrm{M}_{3}$ \\
\hline $\mathrm{M}_{\mathrm{i}}=\mathrm{X}_{\mathrm{i}}$ & $\mathrm{x}_{\mathrm{i}}$ & {$\left[\mathrm{X}_{\mathrm{i}}\right]$} & $\left\{X_{i}\right\}$ & $X_{i}$ \\
\hline
\end{tabular}


International Journal of Business Management and Economic Review

Vol. 4, No. 05; 2021

ISSN: 2581-4664

\begin{tabular}{|c|c|c|c|}
\hline $\begin{array}{l}\text { Unsustainable } \\
\text { Markets }\end{array}$ & $\begin{array}{l}\text { Dictatorship } \\
\text { Markets }\end{array}$ & $\begin{array}{l}\text { Liberal } \\
\text { Markets }\end{array}$ & $\begin{array}{l}\text { Equal and Free } \\
\text { Markets }\end{array}$ \\
\hline Fully imperfect & True imperfect & True imperfect & True perfect \\
\hline Markets & Markets type 1 & Markets type 2 & Markets \\
\hline
\end{tabular}

Implications from Table 2 with respect to model $\mathrm{Mi}=\mathbf{X i}$

a) We can see in column $M_{0}$ that when model Mi takes a fully imperfect market form $\left(X_{\text {ief }}\right.$ $=\mathrm{x}_{\mathrm{i}}$ ) then any market $\mathrm{Mi}$ is a fully unsustainable market as there is no equality and there is no freedom; b) We can appreciate in column $\mathrm{M}_{1}$ that when market Mi takes the form of a true imperfect market type 1 then any market $\mathrm{Mi}$ is a dictatorship based market $\left(\mathrm{X}_{\mathrm{iEf}}=[\mathrm{Xi}]\right)$ as there is no dominant component freedom; c) we can read in column $\mathrm{M}_{2}$ that when market Mi takes the form of a true imperfect market type 2 then any market Mi is a freedom based liberal market $\left(\mathrm{X}_{\mathrm{ieF}}\right.$ $\left.=\left\{X_{i}\right\}\right)$ as equality does not matter; and $\mathrm{d}$ ) we can see in column $\mathrm{M}_{3}$ that when market Mi takes a true perfect market form $\left(\mathrm{X}_{\mathrm{EF}}=\mathrm{X}\right)$ as there is dominant component equality and freedom at the same time then any market Mi is an equal and free market as then full inclusion matters.

\section{General implications:}

1- The necessary and sufficient conditions for a true perfect market(TPM $\left.\mathrm{X}_{\mathrm{X}}\right)$ to exist in a system based on dominant component dominance such as $\mathrm{Mi}=\mathrm{Xi}$ is the existence of both dominant component equality and dominant component freedom at the same time such as in the case of $\mathrm{M}_{3}=\mathrm{Xi}=\mathrm{TPMx}_{\mathrm{i}}$ so that any market Mi where there is dominant component equality and freedom at the same time is a true perfect $\operatorname{market}\left(\mathrm{TPM}_{\mathrm{Xi}}\right)$; and

2- When there is only dominant component equality $\mathrm{X}_{\mathrm{iEf}}$ or there is only dominant

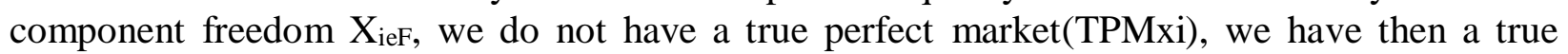
imperfect market(TIMxi), We have then either a true imperfect markets type 1 like $\mathrm{M}_{1}=[\mathrm{Xi}]=$ $\mathrm{TIM}_{1}$ where any market $\mathrm{Mi}$ is a dictatorship based market or we have a true imperfect market type 2 like $\mathrm{M}_{2}=\{\mathrm{Xi}\}=\mathrm{TIM}_{2}$, where any market $\mathrm{Mi}$ is a freedom based liberal market.

\section{Applying the general dominant component perfect market variability theory based on equality and freedom under externality neutrality assumptions to the dominant economy market}

If we assume that the model $\mathrm{Mi}=\mathrm{Xi}$ is the dominant economy market $(\mathrm{DEM}=\mathrm{B})$ so that $\mathrm{Mi}=\mathrm{DEM}$ and $\mathrm{Xi}=\mathrm{B}$, then we can see the model variability of the dominant economy market as indicated in Table 3 below:

\section{Table 3}

The case of the dominant economy market, $\mathrm{Mi}=\mathrm{DEM}$ so $\mathrm{Xi}=\mathrm{B}$ since $\mathrm{Mi}=\mathrm{Xi}$ and $\mathrm{DEM}=\mathrm{B}$

\begin{tabular}{|c|c|c|c|c|}
\hline & $\mathrm{M}_{0}$ & $\mathrm{M}_{1}$ & $\mathrm{M}_{2}$ & $\mathrm{M}_{3}$ \\
\hline $\mathrm{DEM}=\mathrm{B}$ & $\mathrm{b}$ & [B] & $\{B\}$ & B \\
\hline
\end{tabular}


International Journal of Business Management and Economic Review

Vol. 4, No. 05; 2021

ISSN: 2581-4664

\begin{tabular}{|c|c|c|c|}
\hline $\begin{array}{l}\text { Unsustainable } \\
\text { Market }\end{array}$ & $\begin{array}{l}\text { Dictatorship } \\
\text { Market }\end{array}$ & $\begin{array}{l}\text { Liberal } \\
\text { Market }\end{array}$ & $\begin{array}{l}\text { Equal and Free } \\
\text { Market }\end{array}$ \\
\hline $\begin{array}{l}\text { Fully imperfect } \\
\text { Market }\end{array}$ & $\begin{array}{l}\text { True imperfect } \\
\text { Market type } 1\end{array}$ & $\begin{array}{l}\text { True imperfect } \\
\text { Market tvpe } 2\end{array}$ & $\begin{array}{l}\text { True perfect } \\
\text { Market }\end{array}$ \\
\hline
\end{tabular}

\section{Implications:}

1) the necessary and sufficient condition for a true perfect economy market(TPEM $\left.\mathrm{T}_{\mathrm{B}}\right)$ to exist as indicated in column $\mathrm{M}_{3}$ is the existence of dominant component equality and dominant component freedom at the same time so that $\mathrm{TPEM}_{\mathrm{B}}=\mathrm{M}_{3}=\mathrm{B}_{\mathrm{EF}}=\mathrm{B}$. Therefore, there is economic equality and economic freedom at the same time here;

2) the necessary and sufficient condition for a liberal economy model to exist as indicated in column M2 is the existence of dominant component freedom only so that $\mathrm{M}_{2}=\mathrm{B}_{\mathrm{eF}}=\{\mathrm{B}\}$ is a liberal economy model. Hence, there is economic freedom without equality here;

3 ) the necessary and sufficient condition for a dictatorship based economy model to exist as indicated in column M1 is the existence of dominant component equality only so that $\mathrm{M}_{1}=$ $\mathrm{B}_{\mathrm{Ef}}=[\mathrm{B}]$ is a dictatorship based economy model. So there is economic equality without freedom here; and

4) the necessary and sufficient condition for a fully unsustainable economy model to exist as indicated in column $\mathrm{M}_{0}$ is the absence of dominant component freedom and of dominant component equality at the same time so that $\mathrm{M}_{0}=\mathrm{B}_{\mathrm{ef}}=\mathrm{b}$ is a fully unsustainable dominant economy model.

Notice that the structure of the true imperfect model $M 2=\{B\}$ reflects the actual structure of Adam Smith's traditional perfect market model where economic freedom without equality is the central norm. Hence, Adam Smith's traditional perfect market model is not a true perfect economy market model(TPEMB $)$ as $M_{2} \neq M_{3}$. Hence, Adam Smith's traditional market model is a true imperfect market model type 2 as $M_{2}=\{B\}=$ TIM $_{2}$.

Applying the general dominant component perfect market variability theory based on equality and freedom under externality neutrality assumptions to the dominant society market

If we assume that the model $\mathrm{Mi}=\mathrm{Xi}$ is the dominant society market(DSM $=\mathrm{A})$ so that $\mathrm{Mi}=\mathrm{DSM}$ and $\mathrm{Xi}=\mathrm{A}$, then we can see the model variability of the dominant social market as shown in Table 4 below:

\section{Table 4}

The case of the dominant society market, $\mathrm{Mi}=\mathrm{DSM}$ so $\mathrm{Xi}=\mathrm{A}$ since $\mathrm{Mi}=\mathrm{Xi}$ and $\mathrm{DSM}=\mathrm{A}$

\begin{tabular}{|c|c|c|c|c|}
\hline & $\mathrm{M}_{0}$ & $\mathrm{M}_{1}$ & $\mathrm{M}_{2}$ & $\mathrm{M}_{3}$ \\
\hline $\mathrm{DSM}=\mathrm{A}$ & $\mathrm{a}$ & {$[\mathrm{A}]$} & $\{\mathrm{A}\}$ & $\mathrm{A}$ \\
\hline
\end{tabular}


International Journal of Business Management and Economic Review

Vol. 4, No. 05; 2021

ISSN: 2581-4664

\begin{tabular}{|c|c|c|c|}
\hline $\begin{array}{l}\text { Unsustainable } \\
\text { Market }\end{array}$ & $\begin{array}{l}\text { Dictatorship } \\
\text { Market }\end{array}$ & $\begin{array}{l}\text { Liberal } \\
\text { Market }\end{array}$ & $\begin{array}{l}\text { Equal and Free } \\
\text { Market }\end{array}$ \\
\hline Fully imperfect & True imperfect & True imperfect & True perfect \\
\hline Market & Market type 1 & Market type 2 & Market \\
\hline
\end{tabular}

Implications:

1) the necessary and sufficient condition for a true perfect social market(TPSM $\mathrm{A})$ to exist as indicated in column M3 is the existence of dominant component equality and dominant component freedom at the same time so that $\operatorname{TPSM}_{\mathrm{A}}=\mathrm{M}_{3}=\mathrm{A}_{\mathrm{EF}}=\mathrm{A}$. Hence, there is here social equality and social freedom at the same time;

2) the necessary and sufficient condition for a liberal social model to exist as indicated in column M2 is the existence of dominant component freedom only so that $M_{2}=A_{e F}=\{A\}$ is a liberal social model. Therefore, there is social freedom, but not social equality here;

3) the necessary and sufficient condition for a dictatorship based social model to exist as indicated in column M1 is the existence of dominant component equality only so that $\mathrm{M}_{1}=\mathrm{A}_{\mathrm{Ef}}=$ [A] is a dictatorship based social model, Hence, there is social equality but no social freedom here; and

4) the necessary and sufficient condition for a fully unsustainable social model to exist as indicated in column $\mathrm{M}_{0}$ is the absence of dominant component freedom and dominant component equality at the same time so that $\mathrm{M}_{0}=\mathrm{A}_{\mathrm{ef}}=\mathrm{a}$ is a fully unsustainable dominant social model.

Notice that the structure of the true imperfect model M1=[A] reflects the actual structure of Karl Marx's red socialism model where social equality without freedom is the central norm. Hence, Karl Marx's red socialism model is not a true perfect social market $\operatorname{model}\left(\mathrm{TPSM}_{A}\right)$ as $\mathrm{M1} \neq \mathrm{M3}$. The red socialism market is a true imperfect market model type 1 as $M 1=[A]=T I M_{1}$, where social equality without freedom prevails.

\section{Food for thoughts}

a) Can a true green market exist without green market freedom? I think No, what do you think?; b) Can a true red market exists without red market equality? I think No, what do you think?; and c) Can true imperfect markets be passed as perfect markets? I think Yes, what do you think?

\section{CONCLUSIONS}

1) It was shown that if there is component equality and component freedom at the same time we have a true dominant component perfect market; and if we only have freedom or equality we have a true imperfect dominant component market; 2) it was exalted that this applies for a specific dominant component market model as well as for any dominant component market model possible; 3) It was pointed out that the necessary and sufficient conditions for the existence of a true perfect economy market was the existence of economic equality and economic freedom at the same time; 4) It was indicated that since the traditional perfect market 
International Journal of Business Management and Economic Review

Vol. 4, No. 05; 2021

ISSN: 2581-4664

model of Adam Smith is based only on economic freedom it is not a true perfect economy market, but a true imperfect economy market type 2 as there is economic freedom without economic equality; 5) It was highlighted that the necessary and sufficient conditions for the existence of a true perfect social market was the existence of social equality and social freedom at the same time; and finally, 6) It was stressed that since the red socialism market model of Karl Marx is based only on social equality it is not a true perfect social market, but a true imperfect social market type 1 as there is social equality without social freedom.

\section{REFERENCES}

Marx, Karl and Friedrich Engels, 1848. Communist Manifesto, Communist League, London, UK

Muñoz, Lucio, 2016a. Beyond Both Red Socialism Thinking and Traditional Market Thinking: What Is the Structure of the Perfect Red Market. In: International Journal of Advanced Engineering and Management Research(IJAEMR), Vol.1, Issue 5, Pp 546-568, India.

Muñoz, Lucio, 2016b. Beyond Green Market Thinking: What would be the Structure of the Perfect Sustainability Market?, In: International Journal of Science Social Studies Humanities and Management (IJSSSHM), Vol. 2, No. 5, May, Ed. Dr. Maya Pant, India.

Muñoz, Lucio, 2016c. Beyond Traditional Market Thinking: What is the Structure of the Perfect Green market?, In: International Journal of Science Social Studies Humanities and Management (IJSSSHM), Vol. 2, No. 5., May, Ed. Dr. Maya Pant, India.

Muñoz, Lucio, 2021. Sustainability thoughts 150: An overview of perfect market variability based on component dominance and binding externality pressures, In: CEBEM-REDESMA Boletin, Año 15, № 8, August, La Paz, Bolivia.

Smith, Adam, 1776. The Wealth of Nations, W. Strahan and T. Cadell, London, UK. 